
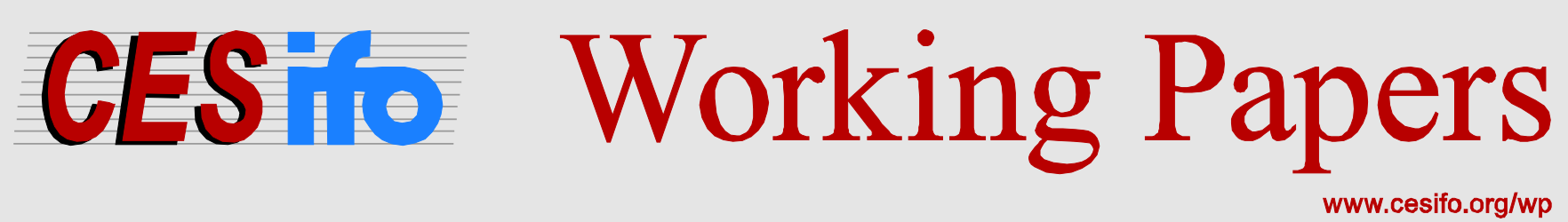

\title{
The Globalization Paradox Revisited
}

\author{
Gregor Schwerhoff \\ Ottmar Edenhofer
}

CESIFO WORKING PAPER NO. 4878

CATEGORY 1: Public FinANCE

JULY 2014

An electronic version of the paper may be downloaded

- from the SSRN website:

- from the RePEc website:

- from the CESifo website:

WWW.SSRN.com

www.RePEc.org

www.CESifo-group.org/wp

\section{CESifo}




\title{
The Globalization Paradox Revisited
}

\begin{abstract}
According to the Globalization Paradox, globalization limits the freedom of choice for national governments. Capital mobility in particular induces tax competition, thus putting downward pressure on capital taxes. However, while capital mobility introduces the inefficiency of tax competition, it makes the allocation of capital more efficient. Whether national welfare and tax-financed public good provision increase or decrease through capital mobility depends on country characteristics. These characteristics include the relative capital endowment, the availability of taxes on fixed factors such as land and the preference for the public good. We compare the two second best settings of a closed economy and an economy with capital mobility to show that the relative capital endowment determines whether the net effect of capital mobility is positive. Fixed factor taxes have the potential to improve welfare by defusing the globalization trilemma through a reduction in the need for capital taxation.
\end{abstract}

JEL-Code: D620, H210, H500, H730, H870.

Keywords: capital mobility, globalization, interjurisdictional competition, public good provision.

\author{
Gregor Schwerhoff \\ Potsdam Institute for Climate Impact \\ Research \\ PO Box 601203 \\ Germany-14412 Potsdam \\ schwerhoff@pik-potsdam.de
}

\author{
Ottmar Edenhofer \\ Potsdam Institute for Climate Impact \\ Research \\ PO Box 601203 \\ Germany-14412 Potsdam \\ ottmar.edenhofer@pik-potsdam.de
}

June 24, 2014

The authors wish to thank Rafael Aigner, Patrick Doupé and Beatriz Gaitan for helpful comments. Gregor Schwerhoff gratefully acknowledges funding from the German Federal Ministry of Education and Research (BMBF) in the Call "Okonomie des Klimawandels" (funding code 01LA1105A CLIPON). Ottmar Edenhofer gratefully acknowledges funding from the German Federal Ministry of Education and Research (BMBF) in the Call "Ökonomie des Klimawandels" (funding code 01LA1105A CLIPON and 01LA1121A CREW). 


\section{Introduction}

Rodrik (2011) supports his claim of a Globalization Paradox with the finding that capital mobility "restricts a nation's ability to choose the tax structure that best reflects its needs and preferences". This is based on empirical evidence that corporate taxes in the European Union decrease over time and that countries engage in tax competition (Devereux et al., 2008; Overesch and Rincke, 2011). More specifically, there is a dominant concern in the literature that capital mobility might result in "less than efficient levels of output of local services" (Oates, 1972). The theoretical understanding of the race to the bottom in capital taxes is based on analytical models such as Zodrow and Mieszkowski (1986).

By pointing out the inefficiency, the literature makes an implicit comparison between the social optimum and the second best equilibrium in capital mobility. In contrast to that we compare the two second best options of an autarkic economy and an economy with capital mobility. This amounts to a cost benefit analysis, which provides a basis to decide whether capital mobility is desirable. Capital mobility might put pressure on tax rates and increase the scope for providing public goods at the same time.

Whether capital mobility is beneficial depends on two major country characteristics, the relative capital endowment and the tax structure. For capital abundant or capital deficient countries the inefficient international allocation of capital in autarky can be worse than the inefficiency due to tax competition when capital is mobile. The comparison of autarky with capital mobility thus provides guidance on how to deal with the empirical observation of declining corporate tax rates and tax competition. Countries importing or exporting large amounts of capital might accept it as part of a development which is beneficial on the aggregate. Countries not participating strongly in capital trade could increase welfare by reducing the mobility of capital.

Rodrik (2011) describes a "globalization trilemma" according to which the nation state, democratic politics and deep economic integration cannot exist at the same time. This "trilemma" is applied to both trade in goods and capital mobility. The only concern about capital mobility is tax competition. This argument, however, is heavily reliant on capital tax based public good financing. We show how a shift from capital taxes towards taxes on fixed factors reduces the inefficiency through tax competition and thus lessens the trilemma concerning capital mobility. These fixed factors could be land as well as immobile forms of 
capital such as capital with adjustment or trade cost. All countries, independent of their capital abundance, would thus benefit from reducing tax competition through a shift towards fixed factor taxation.

Many additional factors influence the net effect of capital mobility, so that we limit our focus on a few crucial aspects. For instance, we only consider residential public services, for which the problem of tax competition was identified. Productive public goods have different properties and would require a different setup. Further, we limit the analysis of other taxes than on capital to fixed factor taxes. This provides a useful simplification of considerations on the tax structure while keeping the focus on mobility.

Fixed factor taxes extenuate tax competition. They might, however, develop some dynamics of their own. If the fixed factor taxes are low, fixed factor owners benefit from capital mobility when imported capital increases the productivity of the fixed factor. If they are too high, the joint effect of capital mobility and fixed factor taxes on net land rents will be negative, even though this joint effect increases aggregate welfare. If fixed factor owners have political power to influence the decision on capital mobility, the government might be constrained to taxing the part of fixed factor rents which is generated through capital mobility.

The early theoretical literature like Wilson (1986) and Zodrow and Mieszkowski (1986) employ small country models with an exogenously given international interest rate. There are gains of capital trade in these models since income can be increased by lending or borrowing capital depending on whether the marginal productivity is higher domestically or abroad. The focus, however, was entirely on the tax competition. We adopt the small country assumption but put the focus on the net effect of capital mobility by comparing it with the second best solution of autarky. Wilson (1986) and Zodrow and Mieszkowski (1986) implicitly compare capital mobility to the social optimum.

Tax competition has also been studied in Nash equilibria between countries. Studies like Hoyt (1991) and Bjorvatn and Schjelderup (2002) assume away the benefits of capital mobility by considering identical countries. Studies like Ogawa and Wildasin (2009) and Eichner and Runkel (2012) assume away the cost of capital mobility by allowing for lump-sum taxes. Papers like Bucovetsky (1991), Wilson (1991) and Bucovetsky and Wilson (1991) do contain both the cost and the benefits of capital mobility. Their focus, however, is on the strategic interaction of asymmetric countries, not on the effect capital mobility has on welfare and 
public good provision.

Empirically, the negative effect of capital mobility on capital taxes seems valid. Bretschger and Hettich (2002) find that capital mobility has a negative effect on corporate taxes. Devereux et al. (2008) show that countries compete over forms of capital taxes and that strategic interaction in taxes is limited to open economies. This last result provides evidence that competition over tax rates does occur and that it is due to capital mobility (as opposed to yardstick competition). It appears less straightforward to empirically establish the effect of capital mobility on public good provision. Liberati (2007) finds that capital mobility is negatively related to government expenditures, but also makes it clear that government expenditures are a problematic proxy for public goods.

Our model adds to the understanding of the link between the tax rate and tax revenue. Capital mobility has two effects. It increases the wealth of an economy by allocating capital more efficiently. As a consequence the economy demands more of the public good. Capital mobility also provides an incentive for tax competition, thus exerting downward pressure on public good provision. It is conceivable that capital mobility is negatively related to government expenditures among countries of similar wealth, but that government expenditures increase when capital mobility is introduced. The reason would be that private expenditure increases more strongly than public good provision.

Bretschger (2010) provides an analysis of how political economy affects the link between capital mobility and public good provision. He assumes that bureaucrats maximize their budget and shows that in this context tax competition exerts a negative effect on capital taxes. Our paper adds two factors which might affect public good provision, the degree of capital imports or exports and the use of non-distortionary taxes. Including these two aspects could further refine empirical tests.

Section 2 describes the model and demonstrates how the situation in autarky and with capital mobility can be compared. Section 3 identifies the roles of capital endowment and land taxation in determining the effect of capital mobility on welfare. Section 4 provides a similar analysis for the level of public good provision. Section 5 shows how considerations for the net land rent could limit the availability of land taxation. Section 6 extends the analysis of Section 3 to gradual increases in capital mobility. Section 7 concludes. 


\section{The model}

\section{$2.1 \quad$ Setup}

We consider an economy which has an endowment of capital ("assets") $a$ and uses capital $k$. Production is a function of capital and a fixed factor called land $l$,

$$
y=f(k, l)
$$

The production function $f$ fulfills the Inada conditions, $f(0, l)=0, f_{k}>0, f_{k k}<0$, $\lim _{k \rightarrow 0} f_{k}=\infty$ and $\lim _{k \rightarrow \infty} f_{k}=0$. The government can use taxes on capital $t_{k}$ and on land $t_{l}$ to provide the public good $g$,

$$
g=t_{k} k+t_{l} l
$$

Assume that the amount of land available for the domestic economy is $\bar{l}$. The taxation of the fixed factor land is assumed to not exceed some fraction of its marginal productivity at full land employment,

$$
t_{l} \leq \alpha f_{l}(k, \bar{l})
$$

where $\alpha \in[0,1]$. The condition $\alpha \leq 1$ ensures that the entire land will be employed by firms. For reasons of political economy, land taxes might be confined to be strictly less than 1 .

The government sets the tax rate to maximize utility from consumption and the public good,

$$
U=U(x, g)
$$

We assume $U(0, g)=U(x, 0)=0$ and that utility is concave in both arguments.

\subsection{The marginal rate of transformation}

Autarky. In autarky, the domestic economy uses its local supply of capital, $k=a$, for production. Both factors are fixed, so that it doesn't matter which factor is taxed. We thus assume $t_{l}=0$. Consumption is given by output less taxation,

$$
x=f(a, \bar{l})-t_{k} a .
$$


The first order condition for the government is $\frac{\partial U}{\partial x} k-\frac{\partial U}{\partial g} k=0$. The government chooses a tax rate $t_{k}$ to equalize the marginal rate of substitution with the marginal rate of transformation,

$$
M R S_{\mathrm{Aut}}=\frac{\frac{\partial U}{\partial g}}{\frac{\partial U}{\partial x}}=1=\frac{\frac{\partial x}{\partial t_{k}}}{\frac{\partial g}{\partial t_{k}}}=M R T_{\mathrm{Aut}} .
$$

Capital Mobility. In the case of capital mobility we have a small open economy. The domestic economy can borrow or lend capital at the international interest rate $\rho$. Firm profit is given as $\pi=f(k, \bar{l})-t_{k} k-\rho k-\left(p_{l}+t_{l}\right) \bar{l}$, where $p_{l}$ is the price of the fixed factor. The firm chooses its capital input according to the first order condition

$$
f_{k}(k, \bar{l})=t_{k}+\rho
$$

Household income is given by the firm's profit plus capital returns and fixed factor earnings, $x=f(k, \bar{l})-t_{k} k-\rho k-t_{l} \bar{l}+\rho a$. Since the capital stock is endogenous we can use (7) to determine how it varies with the capital tax rate,

$$
\frac{d k}{d t_{k}}=\frac{1}{f_{k k}(k, \bar{l})}<0
$$

The government solves

$$
\max _{t_{k}, t_{l}} U\left(f(k, \bar{l})-t_{k} k-\rho k-t_{l} \bar{l}+\rho a, t_{k} k+t_{l} \bar{l}\right)
$$

such that $t_{l} \leq \alpha f_{l}$. The Lagrangian is thus $L=U\left(f(k, \bar{l})-t_{k} k-\rho k-t_{l} \bar{l}+\rho a, t_{k} k+t_{l} \bar{l}\right)+$ $\lambda\left(t_{l}-\alpha f_{l}\right)$. The first order conditions of the government can be written as

$$
\begin{aligned}
U_{x}(-k)+U_{g}\left(k+t_{k} \frac{d k}{d t_{k}}\right)-\lambda f_{l k} \frac{d k}{d t_{k}} & =0, \\
U_{x}(-l)+U_{g} l-\lambda & =0, \\
\lambda\left(t_{l}-\alpha f_{l}\right) & =0 .
\end{aligned}
$$

First assume that the inequality (3) is not binding. Then by (12) we have $\lambda=0$, by (11) we have $\frac{U_{g}}{U_{x}}=1$ and by (10) we have $t_{k}=0$. Now let (3) be binding. Then we obtain $\lambda$ from (11) and can subsitute it into (10). Combining these we obtain the marginal rate of 
transformation under capital mobility $\left(M R T_{\mathrm{Mob}}\right)$,

$$
M R T_{\mathrm{Mob}}= \begin{cases}1 & \text { if } t_{l}<\alpha f_{l} \\ \frac{k+\alpha l f_{l k} \frac{d k}{d t_{k}}}{k+\alpha l f_{l k} \frac{d k}{d t_{k}}+t_{k} \frac{d k}{d t_{k}}} & \text { if } t_{l}=\alpha f_{l} .\end{cases}
$$

Two effects distort the MRT compared to autarky. The term $t_{k} \frac{d k}{d t_{k}}$ represents a Laffer curve effect in taxing capital: The higher the tax rate, the smaller the tax base becomes. The term $\alpha l f_{l k} \frac{d k}{d t_{k}}$ is a tax interaction effect. When the capital tax increases, less capital remains in the domestic economy, thus lowering the marginal productivity of land. This implies that less land taxes can be levied.

Production possibility frontier. The ability of the government to produce combinations of income and the public good by varying the tax rate differs between autarky and capital mobility. In the case of autarky the set of possible combinations is linear, see the left panel of Figure 1. Higher endowments move the production possibility frontier out while an increase in taxation reduces income and increases public good provision.
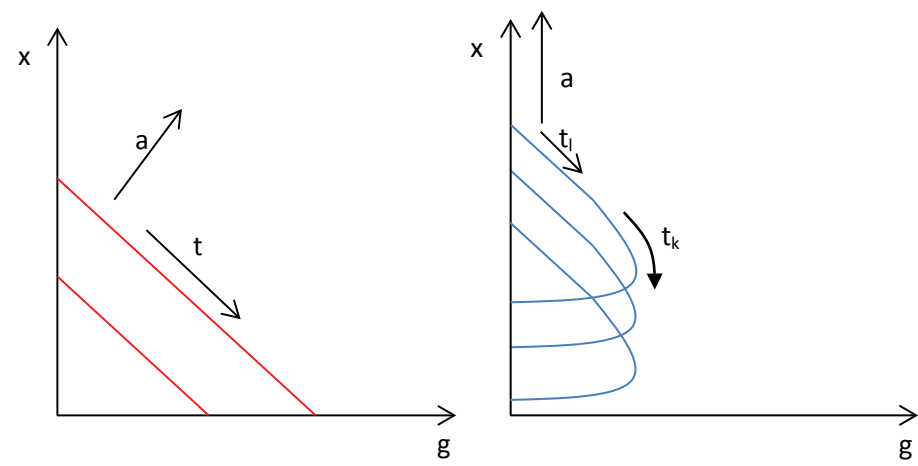

Figure 1: Production possibility frontier in autarky (red) and capital mobility (blue)

In the case of capital mobility, we can distinguish two sections. The first is a linear part, where the government can finance the public good using land taxes. The second part is the one where land taxation is at maximum and capital taxation is used. In this part the government has to take the optimizing behaviour of the firm into account.

Public good provision follows a Laffer curve. For small values, higher tax rates increase the tax revenue, but at some point the tax base reduction dominates and public good provision falls. See the right panel of Figure 1 for an illustration. Public good provision approaches 
zero as taxes approach infinity, because the tax base approaches zero. Further, income is positive even when the economy owns no capital $(a=0)$, because the economy can make positive profits with borrowed capital.

The first order condition of the firm, (7), is independent of the capital endowment $a$. The firm chooses its capital input $k$ as a function of taxes, but without regard for the capital endowment. This implies that the the shape of the production possibility frontier is independent of $a$. Increases in $a$ simply shift the frontier up.

\section{Welfare}

We can now compare welfare for a given $\rho$ and different levels of the exogenous variables $a$ and $\alpha$. There are two opposing effects when capital is mobile. One is the Laffer curve effect, which arises because capital taxes erode the tax base, making it comparatively unattractive to provide the public good. It is given by the term $\frac{d k}{d t_{k}}$ in equation (13). It causes the so called "race to the bottom" and has been described by Zodrow and Mieszkowski (1986) among others.

When the domestic interest rate in autarky does not equal the international interest rate, we also have a gains of trade effect. The gains of trade effect is welfare increasing and is the stronger, the further away the domestic interest rate is from the international rate.

In capital mobility $\rho$ and $a$ jointly determine the amount of capital import or export. In autarky they determine the interest rate differential between the domestic economy and the rest of the world. What matters is their relative position, so that we keep one of them, $\rho$, fixed as a numeraire.

We write $U_{\text {Aut }}^{*}(a, \alpha)$ and $U_{\text {Mob }}^{*}(a, \alpha)$ for the utility in the economy with autarky and capital mobility as a function of the exogenous parameters $a$ and $\alpha$. The asterisk highlights that this is the maximal value chosen by the government. The endogenous variables $k, x, g, t_{k}$ and $t_{l}$ result from this maximization of firms and the government. We assume that the production function and utility function are identical in the two cases. We define values $\underline{a}(\alpha)$ and $\bar{a}(\alpha)$ with the following properties

$$
\begin{aligned}
& \underline{a}(\alpha)=\sup \left\{a \in[0, \infty]: U_{\text {Aut }}^{*}(b, \alpha)<U_{\text {Mob }}^{*}(b, \alpha) \forall b \leq a\right\}, \\
& \bar{a}(\alpha)=\inf \left\{a \in[\underline{a}(\alpha), \infty]: U_{\text {Aut }}^{*}(b, \alpha)<U_{\text {Mob }}^{*}(b, \alpha) \forall b \geq a\right\} .
\end{aligned}
$$


$\underline{a}(\alpha)$ is the value of $a$ where the first intersection of utility occurs, see Figure 2. Below $\underline{a}(\alpha)$ utility in capital mobility is always higher. When $\bar{a}(\alpha)$ is finite it is the last intersection. Above it utility is always higher in capital mobility.

By definition we have $0 \leq \underline{a}(\alpha) \leq \bar{a}(\alpha) \leq \infty$. When all these inequalities are strict we obtain a situation resembling Figure 2. It shows the utility of the economy under autarky (red line) and mobility (blue line) in an example. Below we will investigate which of the inequalities are strict in the general case.

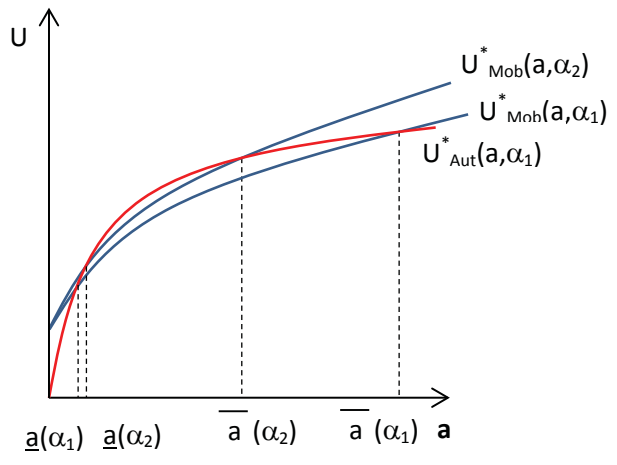

Figure 2: An example: Relative position of utility in capital mobility (blue) and autarky (red) with $\alpha_{1}<\alpha_{2}$.

\subsection{The capital endowment}

In this subsection we focus on the effect of the capital endowment on the net effect of capital mobility and thus set $\alpha=0$.

We first consider the case of very small values of $a$. When the capital endowment is zero, the autarkic economy has zero output, $f(0, l)=0$. Welfare is thus zero. Under capital mobility, the economy can borrow capital from abroad and make profits, since the marginal productivity of capital at zero is infinite. The economy is capable of providing positive amounts of income and public goods and achieves a positive amount of welfare. In addition, welfare is a continuous function of capital. For small values of capital endowment, the gains of trade effect outweighs the "race to the bottom effect".

Next we consider a level of capital endowment $a^{*}$ defined by $f_{k}\left(a^{*}, \bar{l}\right)=\rho$. At this level of the capital endowment, output would be given by $f\left(a^{*}, \bar{l}\right)$ both in the case of autarky and in the case of capital mobility if the government would set zero taxes. The production possibility frontiers in the two economies could be represented as in the left panel of Figure 3. The frontier in the case of mobility would be entirely below that of autarky. Both frontiers 
coincide on the vertical axis and the marginal rate of transformation in capital mobility is always smaller or equal to one, while the MRT in the case of autarky equals to one. Since the frontier in the case of mobility is entirely below that of autarky, welfare must be higher in the case of autarky.
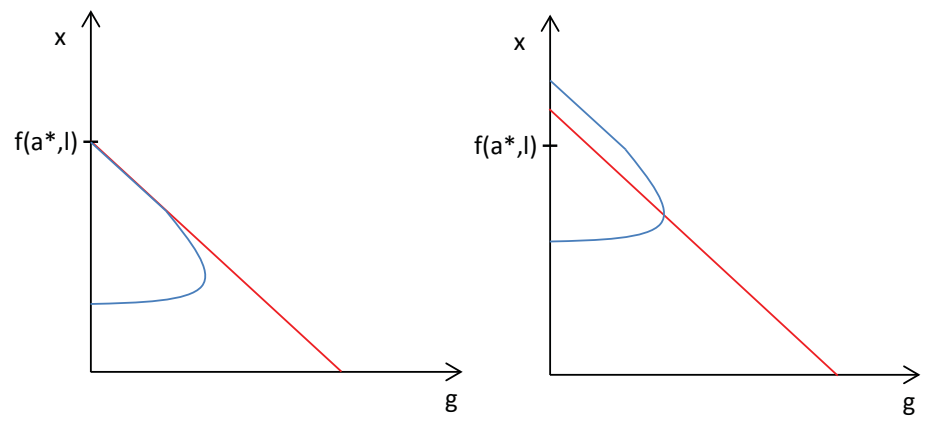

Figure 3: Production possibility frontier in autarky (red) and capital mobility (blue) for a capital endowment of $a^{*}$ (left) and larger than $a^{*}$ (right).

Now assume that $a>a^{*}$ and that the government sets zero taxes. Then the economy with capital mobility can produce with a level of capital $k=a^{*}$ and lend the remainder of the endowment out at the international interest rate. Since the international rate is higher than the domestic marginal productivity of capital at this point, income and public good provision are higher under capital mobility than in autarky as long as capital taxes are zero.

If the government increases capital taxes above zero, public good provision in the autarky case will eventually overtake provision in the mobility case, see the right panel of Figure 3. Therefore, there are always utility functions where utility under capital mobility with the bundle of high income and low public good provision is higher. There are also utility functions where utility under autarky with the bundle of low income and high public good provision is higher.

Proposition 1 Let $\alpha=0$. Then welfare under capital mobility is (i) higher for low values of capital endowment, $0<\underline{a}(0)$, (ii) lower for medium values of capital endowment, $\underline{a}(0)<\bar{a}(0)$, (iii) higher for high values of capital endowment if the household puts a large utility weight on income, $\bar{a}(0)<\infty$, and (iv) lower for high values of capital endowment if the household puts a sufficiently large utility weight on the public good, $\bar{a}(0)=\infty$.

The proposition says that generally, capital mobility is beneficial whenever an economy makes intensive use of capital mobility and not beneficial when the economy makes little use 
of it. An exception to this general rule occurs when the economy has a strong preference for the public good as described in case $(i v)$. In this case the inefficiency of providing the public good is such a drag for the economy that the gains of capital trade do not make up for it.

\subsection{Taxing rents of fixed factors like land}

We now consider how the results in Section 3.1 vary when positive values of the land tax are possible, $\alpha \geq 0$. From the marginal rate of transformation in (13) we can see that an increase in $\alpha$ extends the linear part of the production possibility frontier. The production possibility set for any $\alpha$ is thus a subset of all production possibility sets with $\alpha^{\prime}>\alpha$. Utility can not decrease when $\alpha$ increases. An increase in permissible land taxation has a non-decreasing effect on welfare under capital mobility, $\frac{d a(\alpha)}{d \alpha} \geq 0$ and $\frac{d \bar{a}}{d \alpha} \leq 0$.

Assume that the constraint on land taxation, $t_{l} \leq \alpha f_{l}$, is not binding. Then the economy is unaffected by an increase in $\alpha$. In this case the government chooses a point on the linear part of the production possibility set. It does not benefit from an extension of the frontier.

Assume that the constraint on land taxation is binding. Then the combination of income and public good provision provided by the economy is located on the curved part of the production possibility frontier. It would benefit from the extension of the production possibility frontier generated by the increase in $\alpha$. This is shown formally in the proof of Proposition 2 .

Proposition 2 When the constraint on land taxation is not binding, relaxing the constraint does not increase welfare, $\frac{d U_{M o b}^{*}(a, \alpha)}{d \alpha}=0$. When the constraint is binding, additional land taxation does increase welfare, $\frac{d U_{M o b}^{*}(a, \alpha)}{d \alpha}>0$.

From the aggregate economic view, an increase in $\alpha$ is generally beneficial. As it increases welfare under capital mobility, it also increases the range of capital endowments for which welfare is higher under capital mobility than under autarky. However, any increase in $\alpha$ reduces the net land rent. The effect of this is considered in Section 5 .

Graphically, Proposition 2 means that $\underline{a}(\alpha)$ and $\bar{a}(\alpha)$ converge towards each other as $\alpha$ increases, see Figure 2. The range of values for the capital endowment $a$, where capital mobility is beneficial is increasing in $\alpha$. Depending on the role of land (or fixed resources in general $), \underline{a}(\alpha)$ and $\bar{a}(\alpha)$ might even coincide, so that capital mobility increases welfare for all values of $a$. 


\section{Public good provision}

A government deciding on whether or not to introduce (or increase) capital mobility will be motivated by its effect on welfare as analyzed in Section 3. As long as welfare increases, globalization cannot be considered to have paradoxical effects. However, a similar concern to the one in Rodrik (2011) has been voiced specifically for public good provision. Lorz and Stähler (2001) for example write: "The concern seems to be widespread that international capital mobility threatens national welfare states as governments may find it more difficult to finance public services and redistribution policies with taxes." We identify three parameters we can expect to be important in determining the effect of capital mobility on public good provision: the capital endowment of the economy, the degree of taxes other than on capital available and the preference for the public good.

Not much can be said which holds for any kind of utility function. We thus choose a specific and illustrative utility function, the Leontief utility function,

$$
U(x, g)=\min \left(x, \frac{g}{c}\right)
$$

As the limiting case of the CES utility function with zero elasticity of substitution it has the characteristics of relevance here while being straightforward to handle. The characteristics of relevance are that interior solutions with positive values of both income and the public good are chosen, that small variations in the possibility frontier lead to only small variations in the equilibrium point and that the preference for the public good can be varied in a straightforward way. A disadvantage is that cases where utility is higher but public good provision is lower in capital mobility are ruled out.

The parameter $c$ indicates the utility weight given to the public good. The Leontief utility function can be represented through indifference curves with two perpendicular lines. The intersections of these lines lie on a line through the origin with an inclination of $c$, see Figure 4.

An economy with zero capital endowment $(a=0)$ cannot produce in autarky, but can produce in capital mobility. It will have larger public good provision in capital mobility.

Consider the case of intermediate capital endowment $\left(a=a^{*}\right)$ and zero land tax $(\alpha=0)$. Drawing the indifference curve through the welfare maximizing point under capital mobility shows that there always is a point with higher welfare attainable in autarky, see the left panel 
of Figure 4. In addition, all of these attainable points in autarky are points with higher public good provision. Note that there is a maximum value for public good provision under capital mobility, since high tax rates cause a shrinking of the tax base. If there is a strong preference for the public good this point would be the optimal combination of consumption and public good provision.
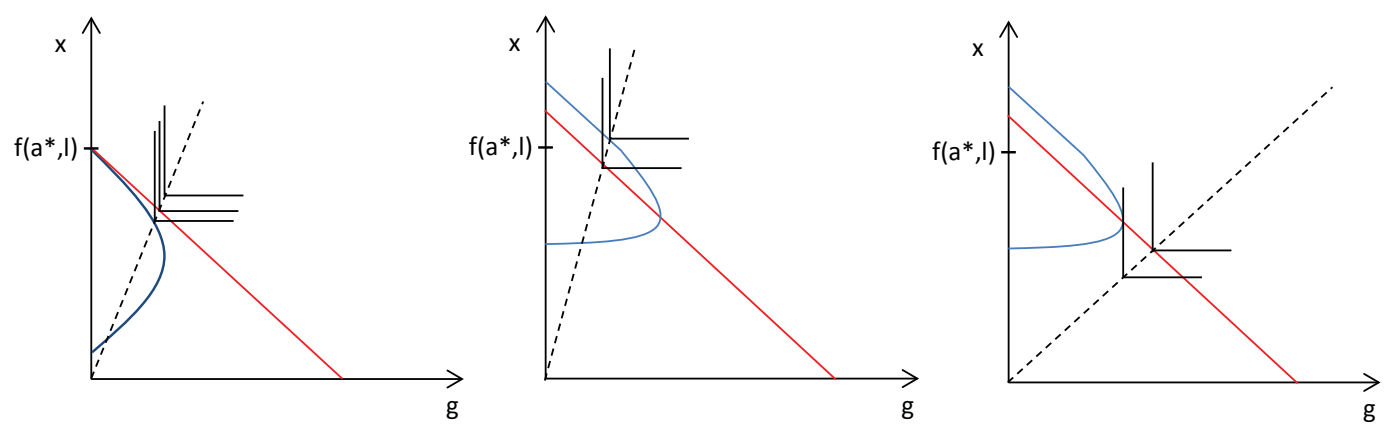

Figure 4: Public good provision with Leontief utility function for capital mobility (blue) and autarky (red). Compared are scenarios with medium capital endowment (left), large capital endowment and low preference for the public good (center) and large capital endowment and high preference for the public good (right).

Proposition 3 Economies with small capital endowments provide more of the public good under capital mobility. For $\alpha=0$ and $a=a^{*}$, economies provide more in autarky.

For large capital endowments $\left(a>a^{*}\right)$, the relative degree of public good provision depends on the preference for the public good, $c$. Let $c$ be low. Then the welfare maximizing point in autarky is within the production possibility set of the economy in capital mobility, see the center panel of Figure 4. The possible combinations of income and public good provision under capital mobility with higher welfare all feature more public good provision.

Let $c$ be so high that the line through the "kinks" in the indifference curves does not intersect the production possibility frontier under capital mobility. Then the welfare maximizing point under capital mobility is the one which maximizes public good provision, see the right panel in Figure 4. The indifference curve through that point admits points in the production possibility set in autarky with higher utility.

Proposition 4 For $\alpha=0$ economies with large capital endowments, provide (i) more public goods when $c$ is large and (ii) less public goods when $c$ is small.

As we have seen in Section 3, a rise in $\alpha$ implies an enlargement of the production 
possibility set under capital mobility: Public goods can be provided at lower cost, so that more combinations of public goods and income can be attained. This means that the interval around $a^{*}$, where autarky provides higher welfare than capital mobility, shrinks. In addition, the maximum level of public goods, which can be provided under capital mobility, increases. Therefore, the range of values for $c$ for which autarky is superior at high levels of $a$, decreases.

Proposition 5 Let the utility weight for the public good, c, be given. Then the range of capital endowments for which capital mobility increases public good provision increases in $\alpha$. Let a be given. Then the range of preference values for the public good, c, for which capital mobility increases public good provision increases in $\alpha$.

\section{$5 \quad$ Fixed factor rents}

In Section 2 we assumed the existence of an exogenous parameter $\alpha$ which limited the degree of land (or generally any fixed factor) rent taxation. Such a limitation is necessary since not all of the land would be employed for production if $\alpha$ exceeded the marginal productivity that land has when the entire available land is used. But there may be reasons why $\alpha$ might be smaller than unity. The government might want to limit land taxation under capital mobility so that the net land rent is no less than the net land rent in autarky. A motivation for this could be to assure political support of land owners for allowing capital to be internationally mobile.

A switch from autarky to capital mobility has ambiguous effects on land rents. If the economy imports capital after the introduction of capital mobility, the land rent increases. At the same time land taxation becomes a more attractive option for raising tax revenue. A ceiling on land taxation would be a way of ensuring that the net effect is not negative.

We employ again the model in Section 2. Let $k^{*}(\alpha)$ and $t_{l}^{*}(\alpha)$ be the equilibrium values of capital and the land tax under capital mobility. The equilibrium is defined in equations (7) and (10) to (12). Land owners are equally or better off under capital mobility if

$$
f_{l}(a, \bar{l}) \bar{l} \leq f_{l}\left(k^{*}(\alpha), \bar{l}\right)-t_{l}^{*}(\alpha) \bar{l}
$$

where the left side is the land rent in autarky and the right side is the net land rent under 
capital mobility. This condition can be rewritten as

$$
t_{l}^{*}(\alpha) \leq 1-\frac{f_{l}(a, \bar{l})}{f_{l}\left(k^{*}(\alpha), \bar{l}\right)}
$$

When the economy owns no capital $(a=0)$, even a confiscatory tax rate $\left(t_{l}^{*}(\alpha)=1\right)$ would not reduce land rents. When the economy is a zero net importer of capital $\left(a=k^{*}(\alpha)\right)$, only a land tax of zero would maintain net land rents. If the economy exports capital, a land rent subsidy would be required to maintain land rents.

\section{Gradual increases of capital mobility}

So far we compared the extreme cases of complete autarky and full capital mobility. This allows an intuitive graphical representation and a less technical analysis. In this section we consider gradual increases of capital mobility and demonstrate that the propositions continue to hold for this case.

We abstract from land taxes by setting $\alpha=0$ and introduce an iceberg cost for trading capital of $\beta$. Given the international tax rate of $\rho$, importing capital costs the domestic economy $\rho+\beta$ per unit of capital and exporting yields $\rho-\beta$. Whether welfare increases following a decrease in transport cost depends on the initial level of transport cost $\beta$, the capital endowment $a$ and the utility function. We illustrate this by tracing out the production possibility frontier.

Assume that $a>0$ and $\rho+\beta<f_{k}(a, \bar{l})$. For small tax rates the capital employed by the domestic economy is determined by $f_{k}(k, \bar{l})-t_{k}=\rho+\beta$, meaning that the economy imports capital. For $t_{k}=0$, public goods and income are given by $g=0$ and $x=f(k, \bar{l})-(k-a)(\rho+\beta)$. For small values of the capital tax, the economy transforms income into the public good at rates of less than one-for-one due to tax competition. For values of $t_{k}$ defined by $\rho-\beta \leq$ $f_{k}(a, \bar{l})-t_{k} \leq \rho+\beta$ the economy is a zero net capital importer. In this range the economy is effectively autarkic, so that marginal increases of the capital tax transform income one-to-one into the public good. For values of $t_{k}$ such that $\rho-\beta<f_{k}(a, \bar{l})-t_{k}$ the economy exports capital and the transformation is again less than one-to-one. See the left panel of Figure 5 for an illustration. 

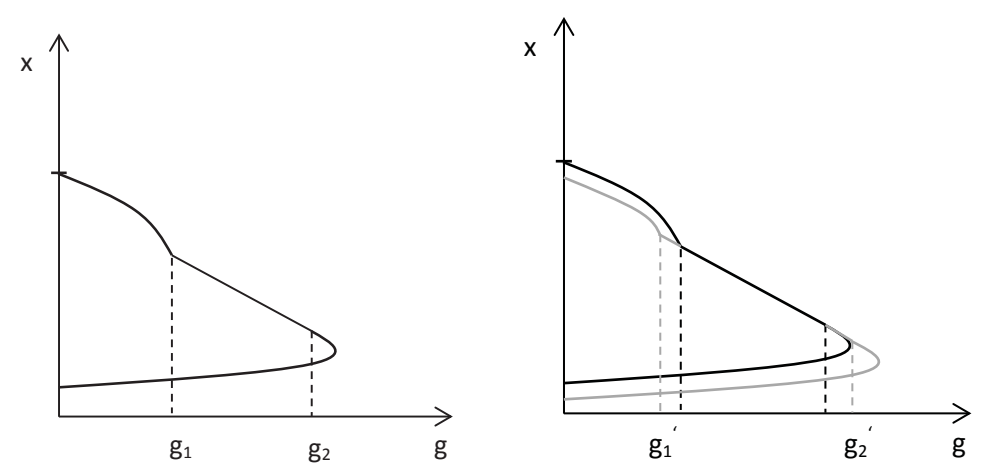

Figure 5: The production possibility frontier with a cost for capital trade (left panel). The right panel illustrates the effect of an increase (in grey) in the trade cost on the frontier.

If the capital endowment is such that $\rho-\beta \leq f_{k}(a, \bar{l}) \leq \rho+\beta$, the economy will be a capital importer for no value of $t_{k}$. If the endowment is so high that $f_{k}(a, \bar{l})<\rho-\beta$, the economy will be a net capital exporter for all $t_{k}$. In these cases the first or the first two of the above described "phases" do not occur. For $a=0$, obviously the autarkic and the exporting phase do not occur.

Having described the production possibility frontier for a given value of $\beta$, we can now consider the effect of a marginal increase in $\beta$. Assume again that $a>0$ and $\rho+\beta<f_{k}(a, l)$. Then for zero capital taxes, income is $x=f(k, \bar{l})-(k-a)(\rho+\beta)$. Obviously an increase in $\beta$ reduces income. At zero capital taxes public good provision is zero so that the frontier moves downward as $\beta$ increases. In addition, the range of taxes for which the economy has zero net capital imports extends. This is the range between $g_{1}$ and $g_{1}^{\prime}$ in the right panel of Figure 5 . The proof of Proposition 6 in Appendix A shows that over the entire range of positive capital imports, the production possibility frontier moves downward.

For a tax level of $\rho-\beta \leq f_{k}(a, \bar{l})-t_{k} \leq \rho+\beta$, the economy is unaffected by an increase in $\beta$ since importing or exporting capital becomes even less attractive. Finally, consider the case of economies which export a very small amount of capital. For these economies we have $\rho-\beta<f_{k}(a, \bar{l})-t_{k}$, but the difference is very small. When $\beta$ increases, the economy will no longer export capital since it would not be profitable. Capital taxation is therefore non-distortionary, so that the production possibility frontier moves up. When an economy exports large amounts of capital then the disadvantages from higher costs of investing abroad may outweigh the advantages of less distorted capital taxation.

Summarizing, we obtain: 
Proposition 6 A marginal decrease in iceberg cost for trading capital (i) increases welfare for capital importing economies, (ii) leaves welfare of zero net importers unchanged and (iii) decreases welfare for at least some capital exporting economies.

Similar to the case of a radical switch from autarky to full capital mobility, we have shown that the welfare effect of a gradual increase of capital mobility depends on the relative endowment of capital. An additional insight of this section is that the welfare effect depends on the level of mobility. Since capital import/export status is endogenous to the parameter $\beta$, an economy of a given endowment might benefit from a further increase when mobility is already high and suffer when it is still low, or vice versa.

When the trade cost of capital increases, capital becomes increasingly similar to a fixed factor. $\beta$ can thus be seen as a measure of the "fixedness" of a factor. For finite and positive values of $\beta$, capital has an intermediate degree of fixedness and shares some properties with fixed factors and others with mobile factors. The analysis in this section can be seen as determining which of the properties are more relevant for a given country.

\section{Conclusion}

This paper suggests a new perspective on capital taxation used for residential public good provision. When capital mobility is increased, one inefficiency (in the international allocation of capital) is traded for another (capital tax competition). The increased difficulty of financing public goods should thus be weighted against the benefits of capital mobility. The comparison of the situation with capital mobility to the social optimum provides no information on whether capital mobility increases welfare. Instead, the comparison demonstrates the scope of benefits to be obtained when replacing capital taxes with taxes on fixed factors like land.

The paper puts a focus on static efficiency. From this view it appears that replacing capital taxes with taxes on fixed factors like land might be the most promising policy option for reducing harmful tax competition. This is in line with major results on capital taxation as in Atkinson and Stiglitz (1976), Judd (1985) and Chamley (1986) who take dynamic and distributional considerations into account. However, we also identify two possible limitations for such a shift. Fixed factor taxes might not raise sufficient revenue so that residual capital taxes remain necessary. Further, the policy would be to the disadvantage of fixed factor owners, who might block the policy for their own benefits just as monopoly owners refuse 
reform in Parente and Prescott (1999).

Taking a broader perspective, the paper shows that in order establish whether globalization has a paradoxical effect requires a comparison of second best settings. Simply pointing out an inefficiency is insufficient to reject a particular policy option, since removing it might introduce an even stronger inefficiency. Capital mobility might decrease the tax rate while increasing welfare and public good provision. 


\section{References}

Atkinson, A. B. and Stiglitz, J. E. (1976). The design of tax structure: direct versus indirect taxation. Journal of public Economics, 6(1):55-75.

Bjorvatn, K. and Schjelderup, G. (2002). Tax competition and international public goods. International Tax and Public Finance, 9:111-120.

Bretschger, L. (2010). Taxes, mobile capital, and economic dynamics in a globalizing world. Journal of Macroeconomics, 32(2):594-605.

Bretschger, L. and Hettich, F. (2002). Globalisation, capital mobility and tax competition: theory and evidence for oecd countries. European journal of political economy, 18(4):695716.

Bucovetsky, S. (1991). Asymmetric tax competition. Journal of Urban Economics, 30(2):167181.

Bucovetsky, S. and Wilson, J. D. (1991). Tax competition with two tax instruments. Regional Science and Urban Economics, 21(3):333-350.

Chamley, C. (1986). Optimal taxation of capital income in general equilibrium with infinite lives. Econometrica, 54(3):607-622.

Devereux, M. P., Lockwood, B., and Redoano, M. (2008). Do countries compete over corporate tax rates? Journal of Public Economics, 92(5):1210-1235.

Eichner, T. and Runkel, M. (2012). Interjurisdictional spillovers, decentralized policymaking, and the elasticity of capital supply. The American Economic Review, 102(5):2349-2357.

Hoyt, W. (1991). Property taxation, nash equilibrium, and market power. Journal of Urban Economics, 30(1):123-131.

Judd, K. L. (1985). Redistributive taxation in a simple perfect foresight model. Journal of public Economics, 28(1):59-83.

Liberati, P. (2007). Trade openness, capital openness and government size. Journal of Public Policy, 27(02):215-247. 
Lorz, O. and Stähler, F. (2001). Who is afraid of capital mobility? on taxation of labor income and the level of public services in an open economy. Journal of Economics, 74(1):79-101.

Oates, W. (1972). Fiscal Federalism. Harcourt Brace Jovanovich, New York.

Ogawa, H. and Wildasin, D. (2009). Think locally, act locally: Spillovers, spillbacks, and efficient decentralized policymaking. The American Economic Review, 99(4):1206-1217.

Overesch, M. and Rincke, J. (2011). What drives corporate tax rates down? a reassessment of globalization, tax competition, and dynamic adjustment to shocks*. The Scandinavian Journal of Economics, 113(3):579-602.

Parente, S. L. and Prescott, E. . (1999). Monopoly rights: A barrier to riches. The American Economic Review, 89(5):1216-1233.

Rodrik, D. (2011). The globalization paradox: why global markets, states, and democracy can't coexist. Oxford University Press.

Wilson, J. (1986). A theory of interregional tax competition. Journal of Urban Economics, 19(3):296-315.

Wilson, J. D. (1991). Tax competition with interregional differences in factor endowments. Regional Science and Urban Economics, 21(3):423-451.

Zodrow, G. and Mieszkowski, P. (1986). Pigou, tiebout, property taxation, and the underprovision of local public goods. Journal of Urban Economics, 19(3):356-370. 


\section{A Proofs}

\section{Proof of Proposition 2}

When the constraint on land taxation is binding, we have $g=t_{k} k+\alpha f_{l} \bar{l}$. Public good provision is maximized at $\frac{d g}{d t_{k}}=k+\alpha \bar{l} f_{l k} \frac{1}{f_{k k}}+t_{k} \frac{1}{f_{k k}}=0$. When the tax is chosen by the government to maximize welfare we have $k+\alpha \bar{l} f_{l k} \frac{1}{f_{k k}}+t_{k} \frac{1}{f_{k k}}>0$.

In addition to the description preceding Proposition 2 we show that the production possibility frontier moves outwards when the constraint is binding, thus increasing the set of attainable combinations of the public good and income.

Consider an economy providing a constant amount of the public good of $\bar{g}$. Assume it wants to maintain public good provision at $\bar{g}$ when $\alpha$ increases. If the attainable level of income at a given $\bar{g}$ increases, the frontier moves up. We determine $\frac{d x}{d \alpha}$ where $x=f(k, \bar{l})-$ $k t_{k}-\rho k-\alpha f_{l} \bar{l}, t_{k} k+\alpha f_{l} \bar{l}=\bar{g}$ and $f_{k}(k, \bar{l})=\rho+t_{k}$.

We obtain

$$
\begin{aligned}
\frac{d x}{d \alpha} & =f_{k} \frac{d k}{d \alpha}-\rho \frac{d k}{d \alpha} \\
& =t_{k} \frac{d k}{d \alpha} .
\end{aligned}
$$

In order to determine the sign of $\frac{d k}{d \alpha}$ we consider an auxiliary function $F$,

$$
F: \mathbb{R} \times \mathbb{R}^{2} \rightarrow \mathbb{R}^{2},\left(\alpha ; k, t_{k}\right) \mapsto\left(\begin{array}{c}
f_{k}(k, \bar{l})-\rho-t_{k} \\
\bar{g}-t_{k} k+\alpha f_{l} \bar{l}
\end{array}\right)
$$

Using the implicit function theorem we have

$$
\frac{d}{d \alpha}\left(\begin{array}{c}
k \\
t_{k}
\end{array}\right)=-\left(\begin{array}{ll}
\frac{\partial F_{1}}{\partial k} & \frac{\partial F_{1}}{\partial t_{k}} \\
\frac{\partial F_{2}}{\partial k} & \frac{\partial F_{2}}{\partial t_{k}}
\end{array}\right)^{-1}\left(\begin{array}{c}
\frac{\partial F_{1}}{\partial \alpha} \\
\frac{\partial F_{2}}{\partial \alpha}
\end{array}\right) .
$$

With this, we have $\frac{d k}{d \alpha}=-\frac{\frac{f_{l}}{f_{k k}} \bar{l}}{k+\frac{t_{k}+\alpha l f_{l k}}{f_{k k}}}>0$ and therefore $\frac{d x}{d \alpha}>0$.

Using the hypothetical economy which maintains public good provision constant we know that the production possibility frontier moves outward when $\alpha$ increase. Therefore, welfare must increase for any kind of utility function when the constraint is binding.

\section{Proof of Proposition 6}

We proceed as in the proof of Proposition 2. In addition to the description preceding 
Proposition 6 we show that the production possibility frontier moves inward for net capital exporters, thus reducing the set of attainable combinations of the public good and income.

Consider an economy providing a constant amount of the public good of $\bar{g}$. Assume it wants to maintain public good provision at $\bar{g}$ when the level of iceberg cost increases. If the attainable level of income at a given $\bar{g}$ decreases, the frontier moves down. We thus determine $\frac{d x}{d \beta}$ where $x=f(k, \bar{l})-(k-a)(\rho+\beta)-k t_{k}, t_{k} k=\bar{g}$ and $f_{k}(k, \bar{l})=\rho+\beta+t_{k}$.

We obtain

$$
\begin{aligned}
\frac{d x}{d \beta} & =f_{k} \frac{d k}{d \beta}-\left(\rho+\beta+t_{k}\right) \frac{d k}{d \beta}-(k-a)-k \frac{d t_{k}}{d \beta} \\
& =-(k-a)-k \frac{d t_{k}}{d \beta} .
\end{aligned}
$$

In order to determine the sign of $\frac{d t_{k}}{d \beta}$ we consider an auxiliary function $G$,

$$
G: \mathbb{R} \times \mathbb{R}^{2} \rightarrow \mathbb{R}^{2},\left(\beta ; k, t_{k}\right) \mapsto\left(\begin{array}{c}
g-t_{k} k \\
f_{k}(k, \bar{l})-\rho-\beta-t_{k}
\end{array}\right)
$$

Using the implicit function theorem we have

$$
\frac{d}{d \beta}\left(\begin{array}{c}
k \\
t_{k}
\end{array}\right)=-\left(\begin{array}{cc}
\frac{\partial G_{1}}{\partial k} & \frac{\partial G_{1}}{\partial t_{k}} \\
\frac{\partial G_{2}}{\partial k} & \frac{\partial G_{2}}{\partial t_{k}}
\end{array}\right)^{-1}\left(\begin{array}{c}
\frac{\partial G_{1}}{\partial \beta} \\
\frac{\partial G_{2}}{\partial \beta}
\end{array}\right)
$$

With this, we have $\frac{d t_{k}}{d \beta}=-\frac{\frac{t_{k}}{f_{k k}}}{k+\frac{t_{k}}{f_{k k}}}>0$. We have $k+\frac{t_{k}}{f_{k k}}>0$ since public good provision reaches its maximum at $k+\frac{t_{k}}{f_{k k}}=0$.

Using $\frac{d t_{k}}{d \beta}>0$ we have $\frac{d x}{d \beta}<0$. Using the hypothetical economy which maintains public good provision constant we know that the production possibility frontier moves inward when capital trade cost increase. Therefore, welfare must decrease for any kind of utility function for capital importing economies. 